\title{
Every death counts: use of mortality audit data for decision making to save the lives of mothers, babies, and children in South Africa
}

\author{
South Africa Every Death Counts Writing Group* \\ (*members listed at end of paper) \\ Correspondence to: Robert Pattinson, MRC Maternal and Infant Heath Care Strategies Research Unit, University of \\ Pretoria, Klinikala Building, PO Box 667 Pretoria 0001, South Africa Robert.Pattinson@up.ac.za
}

\section{Summary}

South Africa is one of the few developing countries with a national confidential inquiry into maternal deaths. 164 health facilities obtain audit data for stillbirths and neonatal deaths, and a new audit network does so for child deaths. Three separate reports have been published, providing valuable information about avoidable causes of death for mothers, babies, and children. These reports make health-system recommendations, many of which overlap and are intertwined with the scarcity of progress in addressing HIV/AIDS. The leaders of these three reports have united to prioritise actions to save the lives of South Africa's mothers, babies, and children. The country is off-track for the health-related Millennium Development Goals. Mortality in children younger than 5 years has increased, whereas maternal and neonatal mortality remain constant. This situation indicates the challenge of strengthening the health system because of high inequity and HIV/AIDS. Coverage of services is fairly high, but addressing the gaps in quality and equity is essential to increasing the number of lives saved. Consistent leadership and accountability to address crosscutting health system and equity issues, and to prevent mother-to-child transmission of HIV, would save tens of thousands of lives every year. Audit is powerful, but only if the data lead to action.

\section{Introduction}

Cape Town, South Africa, is the location for the 2008 Countdown meeting, which aims to track progress towards achievement of the Millennium Development Goals (MDGs) for maternal and child survival. ${ }^{1}$ This meeting provides South Africa with the opportunity to take stock of national progress towards these important goals, which the government has committed to achieving.

In this report, the leaders of three South African national audit reports (Saving Mothers, Saving Babies, ${ }^{\frac{3}{}}$ and Saving Children $^{4}$ ) unite to review national progress towards the MDGs for maternal, neonatal, and child survival; the direct causes of the deaths; the avoidable causes of death that are emphasised by the audit process; and present coverage and quality of care, which is the focus of the Countdown meeting. ${ }^{1}$ These audits show the power of counting every death to improve care, at least at the provider-patient interface, although broad change needs system-wide accountability.

\section{Mortality audit for mothers, babies, and children}

The recent Lancet Who Counts? series drew attention to the absence of reliable data for births, deaths, and causes of death, and the need to count and account for these deaths to 
accelerate and track progress for the MDGs..$^{-}$In Africa, only two countries - the two island states of Mauritius and Seychelles-have complete information about cause of death through vital registration systems. ${ }^{5}$ South Africa has fairly high registration compared with many other African countries. Registration coverage for births can be estimated at $78 \%$ on the basis of registered births ${ }^{\underline{6}}$ and UN-estimated births every year. ${ }^{7}$ However, death registration is lower than birth registration; data obtained in a rural demographic surveillance site showed that less than $30 \%$ of child deaths were registered. $\stackrel{8}{-}$ Furthermore, certificates for cause of death can systematically miss some causes. ${ }^{[9]}$ and [10] Hence, vital registration data do not provide reliable national tracking of the numbers or causes of death, especially death in children and babies. Several nationally representative surveys of maternal, neonatal, and child mortality have been done, but none within the past 5 years.

National facility-based mortality audits for maternal, perinatal, and child deaths are an important source of data for action in South Africa. Maternal mortality is audited through the National Committee on Confidential Enquiries into Maternal Deaths (NCCEMD), and is notable since South Africa is the only developing country to have such a processa mechanism that is regarded as crucial to maternal survival and quality of care in many European countries. Additionally, stillbirths and neonatal mortality are recorded through the Perinatal Problem Identification Programme (PPIP), $\underline{3}$ and child mortality through the Child Healthcare Problem Identification Programme (Child PIP) ${ }^{4}$ (panel 1). The national audit reports are a powerful source of data, and have generated interest in other countries, such that the African Union is looking at helping develop their use more widely in Africa.

\section{Panel 1. Overview of South African national mortality audit data reports}

\section{Saving Mothers: confidential inquiry into maternal deaths in South Africa (NCCEMD) ${ }^{2}$}

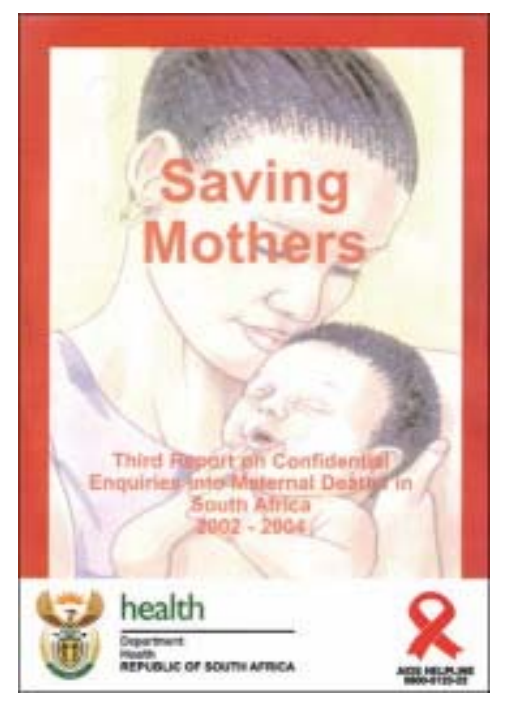

Includes: maternal deaths

Data coverage: aims to capture all maternal deaths; present coverage limited to facilities (roughly $84 \%$ of 
births)

Numbers: 1173 maternal deaths reported in 2004 (3406 maternal deaths for 2002-04)

Frequency: one report for 1998, and thereafter every 3 years

Coordination: reported to the National Committee on Confidential Enquiries into Maternal Deaths

Report: http://0-www.doh.gov.za.innopac.up.ac.za/docs/reports/2004/savings.pdf

\section{Saving Babies: Perinatal Problem Identification Programme (PPIP) ${ }^{\frac{3}{3}}$}

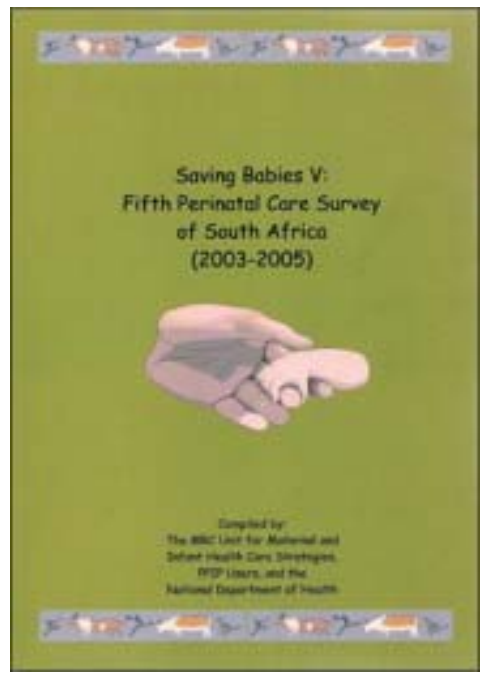

Includes: stillbirths and neonatal deaths before discharge

Data coverage: 164 facilities reported information about 576065 births between 2003 and 2005, which was $20 \%$ of national births

Numbers: 4067 stillbirths and 2887 early neonatal deaths audited, yearly average 2003-05

Frequency: every year for 2000-02, every 2 years since 2003

Coordination: compiled by the audit users, MRC Unit for Maternal and Infant Healthcare Strategies, with the National Department of Health

Report: http://www.ppip.co.zaf

\section{Saving Children: Child Healthcare Problem Identification Programme (Child PIP) ${ }^{4}$}

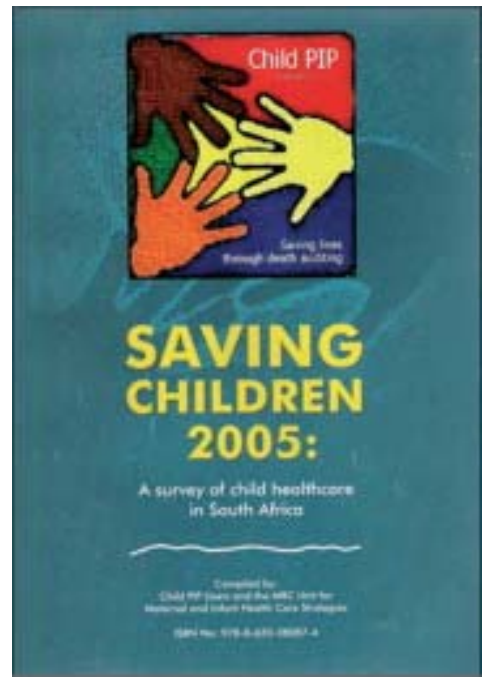


Includes: infants and children (birth to 18 years), admitted to paediatric wards

Data coverage: 28 facilities across South Africa provided information about 56973 admissions, 3\% of

child deaths

Numbers: 1961 child deaths audited, yearly average 2005-06

Frequency: every year since 2004

Coordination: compiled by the audit users, MRC Unit for Maternal and Infant Healthcare Strategies, with the National Department of Health

Report: http://www.childpip.org.za

\section{Every Death Counts ${ }^{11}$}

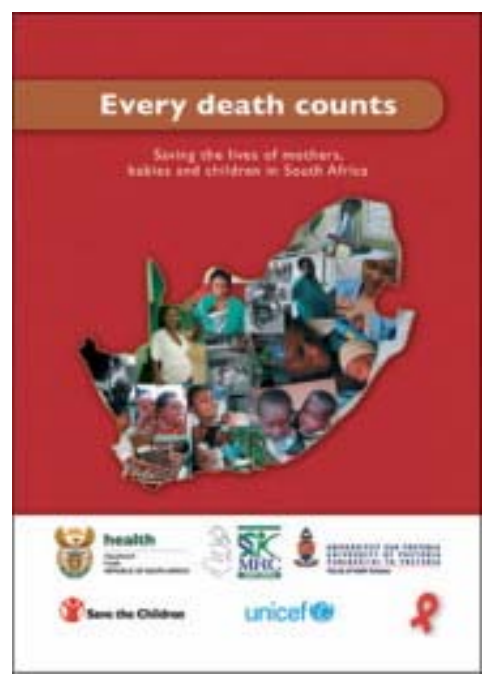

Includes: maternal, neonatal, and child deaths, plus stillbirths

Inputs: the three national audit reports, with additional national data for tracking for progress and recommendations that are cross cutting

Coordination: compiled by the teams that lead the three audit reports, with the National Department of Health, MRC Unit for Maternal and Infant Healthcare Strategies, MRC Burden of Disease and MRC Health Systems internal units, and Save the Children

Report: $\underline{\text { http://0-www.childpip.org.za.innopac.up.ac.za/everydeathcounts }}$

All three of these audits apply a common audit cycle that takes data to action with four steps: (1) record every death and the direct and underlying medical cause, and discuss in a non-condemnatory way the modifiable factors within the health system or beyond; (2) synthesise data (for every site and across sites) and identify local and national priorities for action to reduce deaths; (3) make recommendations for action and implement these actions; and (4) assess whether recommendations have been undertaken.

Although the steps are much the same for the three South African national audits, the coordination, coverage, and processes vary (panel 1). The NCCEMD has been appointed by the Minister of Health since 1997 and is coordinated by the Maternal, Child, and Women's Health and Nutrition cluster within the National Department of Health. The Saving Mothers audit process aims to obtain data for all maternal deaths to capture 
causes, avoidable factors, and substandard care related to every death to identify trends and areas for improvement. Maternal deaths are reported to the provincial Maternal, Child, and Women's Health coordinators through the completion of a maternal death notification form and submission of copies of the case notes. Provincial assessors analyse every case with respect to primary and final causes of death, and suboptimum care that was received. These assessors' reports are then sent to a national committee for collation and analysis of the deaths. Recommendations for the care of pregnant mothers are made by the national committee in a report that has to be cleared by the Minister of Health.

PPIP is a facility-based audit of perinatal deaths (ie, stillbirths and neonatal deaths that occurred before discharge from hospital) which was developed in South Africa in the

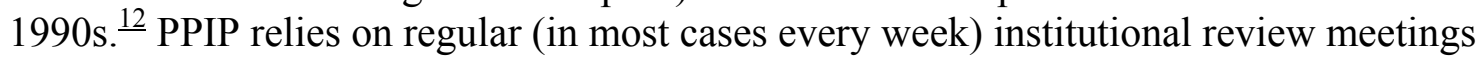
to discuss perinatal deaths and possible shortcomings in care (a so-called grassrootsupwards process). At present, data from 164 health facilities (mostly hospitals) are collated, capturing about $20 \%$ of births in South Africa. A clinical classification of perinatal deaths is used since access to post-mortems and placental histology is scarce, and modifiable factors are recorded. The data are used for local quality improvement, and also entered into databases in every facility with software that is freely available from PPIP. Data collection, reporting, and entry into the software can be done by midwives. Data are summarised in a triennial report that is linked to national and provincial Departments of Health, providing recommendations for action on the basis of the data.

The Child PIP programme provides the means and process to review paediatric deaths in hospital by identification of deaths; assignment of a cause to every death; and identification of the HIV and nutritional status and social context for every child who dies, as well as modifiable factors in the care received. Child PIP needs a doctor or paediatric nurse to collect and enter data onto the Child PIP software programme. Data from Child PIP is used for local quality improvement through the mortality review meeting process, but is also collated nationally in a yearly publication. Originally adapted from PPIP in 2001, Child PIP is used in more than 50 hospitals throughout the country, but the data referred to in this report are based on collated data from 28 sites. Facility coverage of Chid PIP has increased substantially in a short time, emphasising the demand from health-care providers; however, less than $6 \%$ of child deaths are covered nationally.

The success of audit is dependent not only on data collection, but also on subsequent action. All three audit processes have stories of success of data to action locally, where health-care providers have used the data to change local programmes (panel 2). For example, providers in one of the first hospitals to undertake Child PIP used the data to guide them to improve quality of counselling for prevention of mother-to-child transmission of HIV; a substantial 37\% drop in the inpatient death rate was recorded the next year. ${ }^{[13]}$ and ${ }^{[14]}$ PPIP data helped to catalyse the scale-up of Kangaroo Mother Care (KMC) - a method of caring for small babies whereby the baby is tied to the mother's front, promoting warmth and breastfeeding, and preventing infections - in 70 hospitals across South Africa and to provide a before and after assessment of mortality reduction. In addition to local action, national action can be taken through recommendations in the reports. The recommendations presented in the Saving Mothers reports are approved by 
the Minister of Health and are incorporated into the strategies for maternal and child health care both nationally and for every province. The recommendations in Saving Babies and Saving Children are made in collaboration with the National Department of Health, but are not necessarily official policy. Despite the clear links between the audit process and the National Department of Health, the 2002-04 Saving Mothers report showed that very few of the recommendations for reduction of maternal deaths in South Africa that were made in previous reports had been implemented. $\stackrel{2}{ }$ For example, only one of nine provinces achieved the goal of half of ambulances arriving within $1 \mathrm{~h}$ of being called, because of shortages in emergency-service vehicles and personnel and the centralisation of emergency services. ${ }^{2}$

\section{Panel 2. Use of mortality audit data in South Africa-do the data lead to action?}

\section{Saving Children (Child PIP)}

Example at the provider-patient interface $e^{4}$

Problem: The Child PIP data showed that nearly $89 \%$ of children dying in 2005 in Witbank hospital, Mpumalanga, were either exposed to or infected with HIV, and that $44 \%$ of the deaths were due to Pneumocystis jirovecii. The paediatric team at Witbank Hospital reviewed the data for the prevention of mother-to-child transmission of HIV, which showed that $71 \%$ of HIV-infected mothers whose children were dying had not received nevirapine. When only $15 \%$ of mothers agreed to be tested, counselling practices were investigated. The low testing rate was thought to be because of poor understanding of HIV, and vertical transmission prevention on the part of both counsellors and mothers, and because only opt-in, group counselling was offered.

Actions: The team improved individual counselling, with opt-out testing encouraged. Within a few months, $85 \%$ of mothers were being tested.

Result: Health-care providers at Witbank Hospital used audit data from the Child PIP to identify a substantial problem, implement a solution, and monitor change. The Child PIP data from the following year showed an almost $60 \%$ decrease in Pneumocystis jirovecii deaths, with a significant decrease of $37 \%$ in the inpatient death rate for children.

\section{Saving Babies (PPIP) \\ Example at the policy and province level with high population coverage $e^{[13]}$ and [14]}

Problem: Complications of preterm birth account for $45 \%$ of all neonatal deaths in South Africa, which is the largest cause of such deaths. These small babies need extra care and warmth, and incubators are not always available.

Actions: $\mathrm{KMC}$ is a method of caring for small babies whereby the baby is tied to the mother's front, promoting warmth and breastfeeding, and preventing infections. It is a low-cost and resource-efficient method that encourages early discharge and needs fewer nursing staff since the mother does most of the caring. KMC was first introduced into the Western Cape in the mid-1990s, but was only being practised in a few sites when Saving Babies started. There has been systematic large scale roll-out, with increases in the number of facilities providing $\mathrm{KMC}$ as well as supervision and quality tracking. The audit process has also facilitated local quality improvement in care - eg, job aids for feeding of preterm babies.

Result: In 70 hospitals, $90 \%$ of those surveyed reported that they had implemented KMC by January, 2005, varying between sporadic KMC (2.3\%), intermittent (41\%), continuous (17\%), and both intermittent and continuous KMC (34\%). 24 institutions reported that they had created a special ward for KMC..$^{-1}$

According to PPIP data, hospitals that have introduced $\mathrm{KMC}$ have seen a $30 \%$ decrease in neonatal mortality from at least 6 months before the introduction of $\mathrm{KMC}$ to at least 6 months after its introduction. Neonatal mortality in babies weighing between $1 \mathrm{~kg}$ and $2 \mathrm{~kg}$ in hospitals using KMC is $20 \%$ lower than it is in hospitals not using this method.

Saving Mothers (NCCEMD)

Example at national level ${ }^{2}$ 
Problem: In direct obstetric cause of death and particularly for intrapartum stillbirth, a frequently identified avoidable cause of death is incorrect management of labour, especially absence of use or incorrect use of the partograph.

Actions: In the Saving Mothers 1999-2001 report, ten trackable recommendations were made.

Recommendation seven stated "Correct use of the partograph should become the norm in each institution conducting births. A quality assurance programme should be implemented, using an appropriate tool". The target set was for $30 \%$ of all institutions to have a quality assurance programme by December, 2004. A generic method was developed for local adaptation and use.

Result: The recommendations from the 1999-2001 reports, including recommendation seven, were assessed In the 2002-04 report (published in 2007). Audit data obtained in 2004 from eight of nine provinces showed that all but one province had facilities that started quality assurance programmes, with coverage ranging from $18 \%$ to $100 \%$. However, not all facilities were using the programme and the use of the programme did not correlate well with scoring correct use of the partograph. The provinces associated "poor/lack of and/or incorrect use of the partograph with shortage of staff, high turn over and allocation of inexperienced personnel". Hence, although audit resulted in improvements in quality process, the effect was limited by the scarcity of widespread change of practices, and the need for accountability for change and investment at a higher administrative level.

Child PIP $=$ Child Healthcare Problem Identification Programme. PPIP=Perinatal Problem Identification Programme. NCCEMD=National Committee on Confidential Enquiries into Maternal Deaths. KMC=Kangaroo Mother Care.

These audits represent an important step forward in quality improvement. Their main purpose is to identify avoidable or modifiable factors and implement local solutions. The reports can also act as a source for mortality data, with some restrictions - eg, the fact that these audits were not designed to obtain population-based, representative data unless all deaths occur in facilities and all facility deaths are captured. None of the three audits has data for deaths that arose outside of a health facility, even though an estimated $15 \%$ of deliveries take place in such circumstances. $\frac{15}{}$ To obtain a complete picture of maternal, perinatal, and child mortality, the strengthening of vital registration or capturing of information about non-facility deaths though verbal autopsy surveys will be crucial. $\stackrel{16}{ }$ HIV assessment as represented by testing and staging during admission to hospital was missing for half the deaths in both NCEMD and Child PIP, which is a proxy for poor quality of care received.

\section{Progress towards child survival and maternal health}

Audit is a useful method, but the final goal is mortality reduction. Are maternal, newborn, and child deaths nationally being reduced or not in South Africa? Although debate surrounds national mortality figures and estimates, all indications are that maternal and child mortality has increased since the baseline for the MDGs in 1990 (figure 1). ${ }^{23}$ Data for maternal mortality since 1998 are available through the national confidential inquiry, and the reported maternal mortality ratio has risen every year, from 117 per 100000 in 1998 to 147 in 2004 (the last year with official data). ${ }^{2}$ Preliminary analysis of the most recent confidential inquiry data suggests an even higher maternal mortality ratio than that reported. Although some of this increase is artifact because of improved reporting of deaths, other data suggest an increase in maternal mortality ratio over time in sites with high-quality data. [2], [24], [25] and [26] The UN estimates ${ }^{[22]}$ and [27] and other national data such 
as a census in $2001^{\frac{24}{4}}$ suggest that the ratio ranges from 230 per 100000 to 575 per 100000 (figure 1).

\section{A MDG 4}

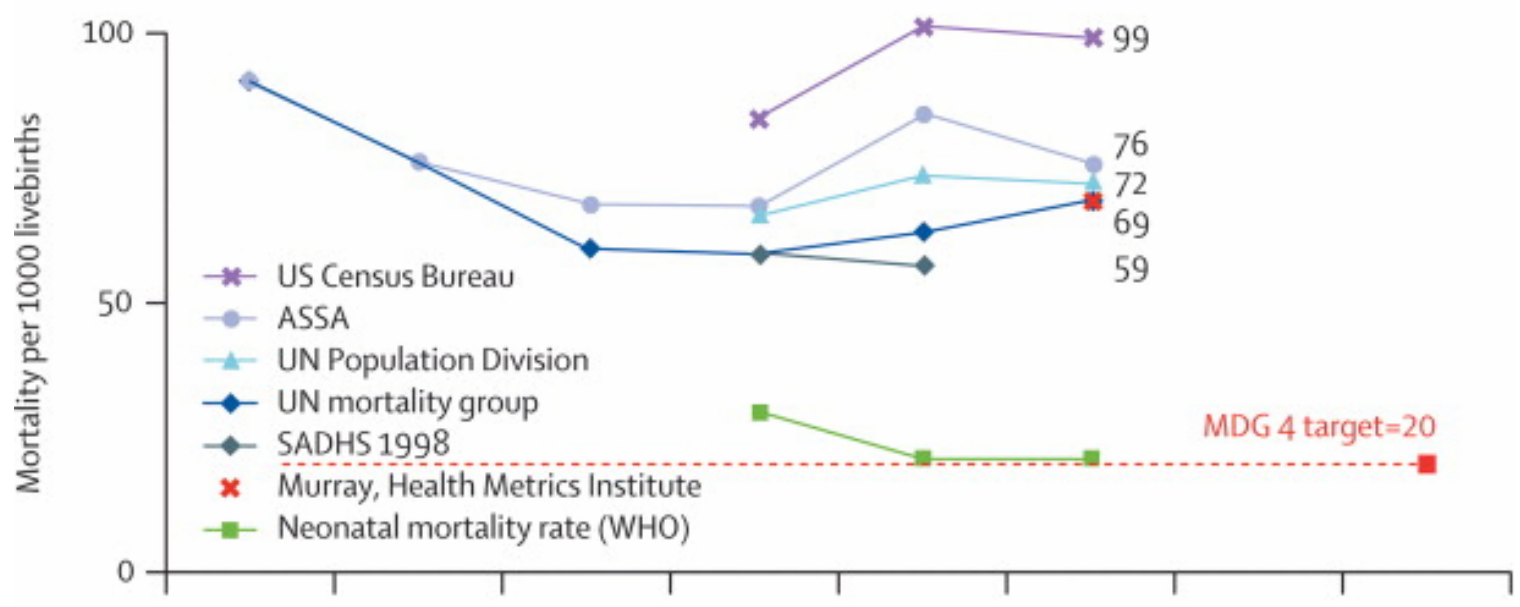

\section{B MDG 5}

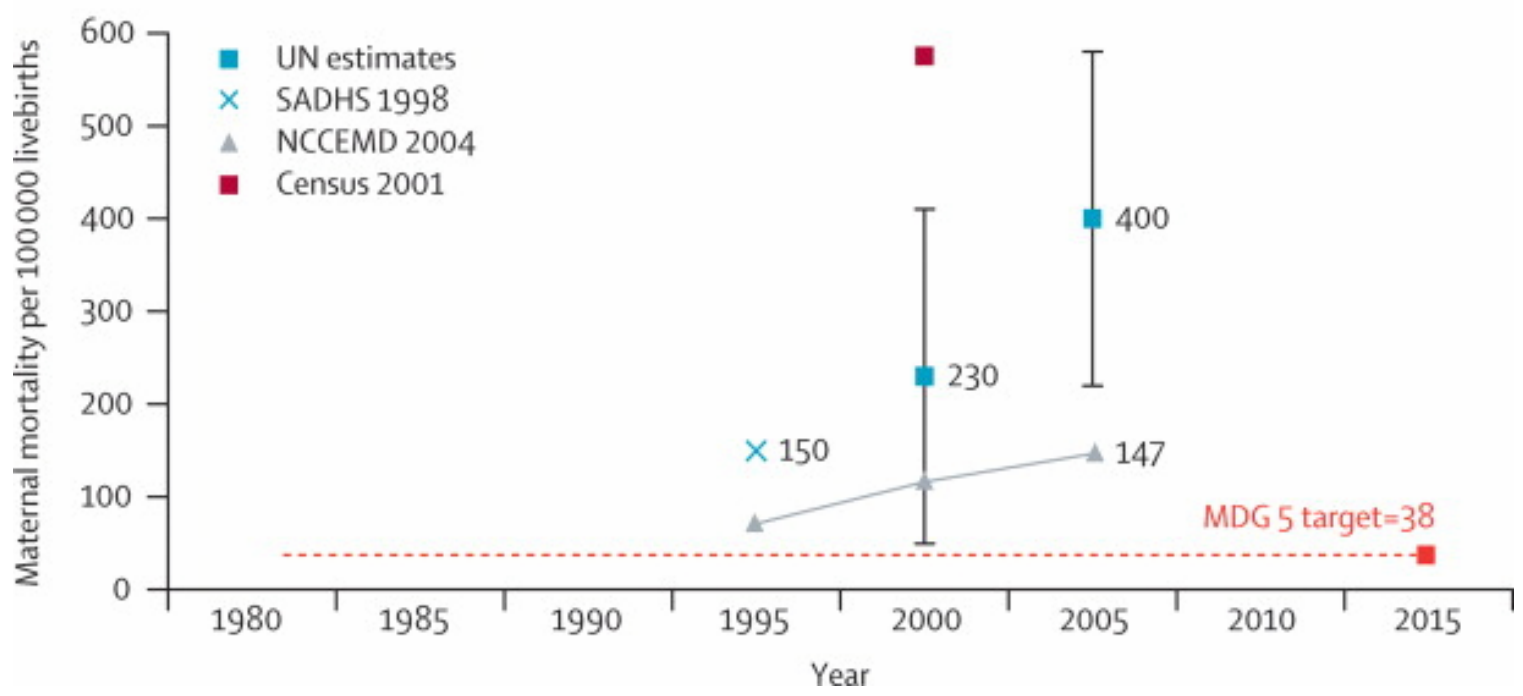

Figure 1. Rate of progress to child survival (MDG 4) (A) and maternal health (MDG 5) (B) in South Africa

Reproduced from Every Death Counts report ${ }^{11}$ with permission from author and publisher. Data from UN Interagency group for child mortality estimation, ${ }^{7}$ ASSA estimate modelled by R E Dorrington and co-workers, ${ }^{17}$ Health Metrics Institute, ${ }^{18}$ US Census Bureau, $\stackrel{19}{=}$ UN Population Division, ${ }^{20}$ neonatal mortality rate from WHO,$\frac{21}{}$ UN Interagency group for maternal mortality estimation, $\underline{22}$ South Africa Demographic and Health Survey,,$\underline{15}$ and Saving Mothers 2002

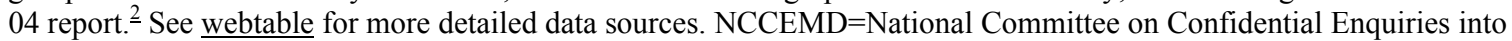
Maternal Deaths. SADHS=South Africa Demographic and Health Survey. ASSA=Actuarial Society of South Africa.

Several point estimates have been reported for national mortality rates in children younger than 5 years, but four of the five estimates for 2005 were between 69 per 1000 and 76 per 1000, all within overlapping uncertainty (figure 1). Although the data are too 
uncertain for us to be sure about present trends, South Africa is one of 12 countries in which the child mortality rate has increased instead of falling since 1990. As a result, South Africa has to now achieve an average yearly rate of reduction of $14 \%$ to meet

MDG 4 by $2015 . .^{28}$ By contrast, some countries that had similar mortality rates to South Africa in 1990 — such as Brazil, Mexico, and Egypt — are on track to meet MDG 4 and have halved their mortality rate for children younger than 5 years since $1990 . \underline{28}$

Most of the increase in maternal and mortality in children younger than 5 years is accounted for by HIV/AIDS. Although the rate of new HIV infections is stabilising ${ }^{29}$ and more children are receiving needed treatment, ${ }^{28}$ nearly a third of pregnant women are HIV-infected - ranging from $15 \%$ in Western Cape province to $39 \%$ in KwaZulu-Natal. $\underline{29}$ Nationally, roughly 300000 women with HIV every year need services for themselves and to prevent mother-to-child transmission. According to Child PIP data, half the children who died had HIV status recorded and $80 \%$ of these children were exposed to or infected with HIV. ${ }^{4}$ Increased coverage and quality of interventions for prevention of mother-to-child transmission are crucial, as is improvement of care of HIV-positive women in their own right. Furthermore, the scarcity of measurable progress in reduction of neonatal mortality contributes to this high child mortality, with deaths during the first month of life accounting for $30 \%$ of all child deaths. ${ }^{11}$

Achievement of the health MDGs in South Africa cannot be done without explicitly addressing inequity. Average mortality rates hide major disparities. Mothers, babies, and children in poor families are at increased risk of illness and face many challenges in accessing timely, high-quality care, with the result that poor children are at least four times more likely to die than are richer children. ${ }^{15}$ Great disparity exists between South Africa's public and private health-care systems. ${ }^{30}$ The public system serves $85 \%$ of the population, but with only about $40 \%$ of total health-care expenditure. ${ }^{31}$ Even though health-care services are free for pregnant women and children younger than 5 years within the public sector, households' direct out-of-pocket payments to health-care providers - including traditional health practitioners - account for nearly $14 \%$ of all health-care expenditure. .31 Distribution and access to essential services are also unequal across South Africa's nine provinces and 52 districts. For example, primary health-care spending is three and a half times more in the district with the highest spending than it is

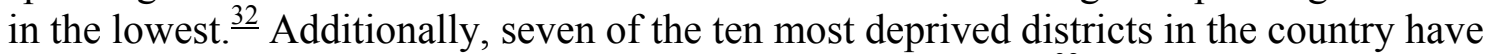
primary health-care expenditure less than the national average. $\underline{\underline{32}}$

\section{Causes of death in mothers, babies, and children}

Data for maternal death gathered by the NCCEMD have shown that the largest cause of maternal death is non-pregnancy related infections, mainly HIV/AIDS, tuberculosis, and pneumonia, accounting for at least $38 \%$ of all maternal deaths (figure 2 ). ${ }^{2}$ However, this finding is probably an underestimate since only $46 \%$ of the women who died were tested for HIV, and 78\% of those who were tested were HIV-positive. Hypertension and haemorrhage (antepartum and postpartum) are major causes of maternal death that are very preventable, and the combined obstetric causes of death account for around half of 
all maternal deaths (54\%). Legalised abortion was introduced with a liberal law in 1997. $\frac{34}{4}$ Abortion now accounts for only $3 \cdot 5 \%$ of registered maternal deaths. ${ }^{2}$

A Why do mothers die?

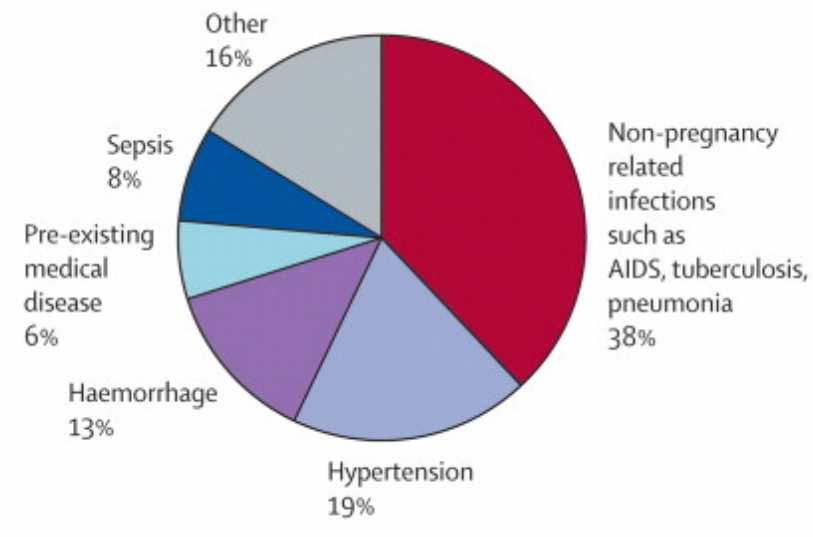

B Why are babies stillborn?

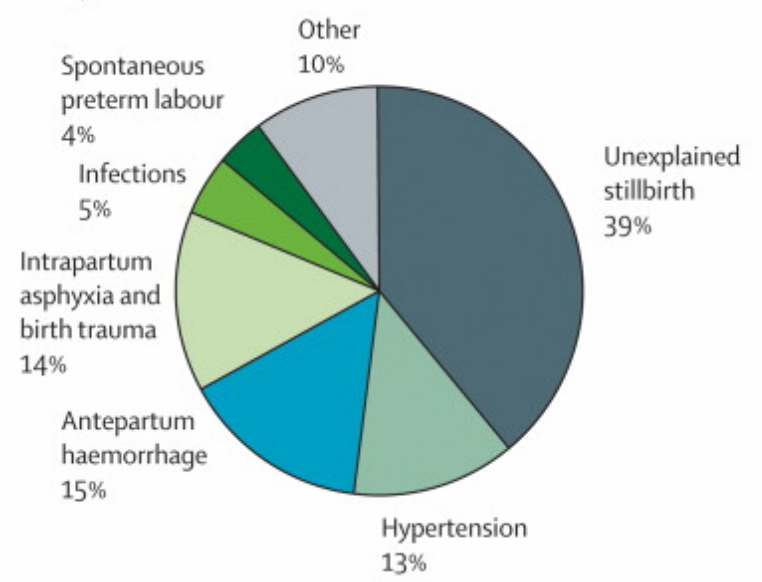

C Why do children and neonates die?

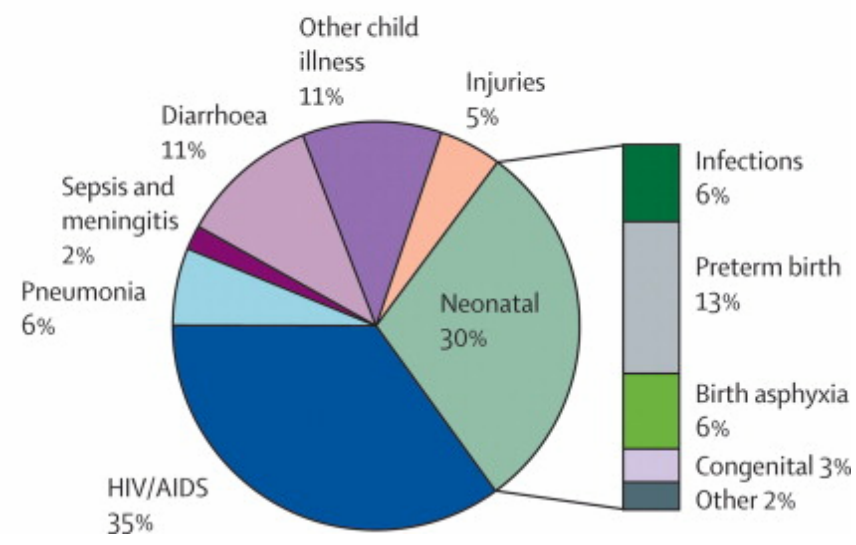

Figure 2. Cause of death in South Africa

(A) Primary causes of maternal death, (B) primary causes of stillbirths (more than $1000 \mathrm{~g}$ or 28 weeks), and (C) causes of death for children younger than 5 years and neonates (babies younger than 28 days). Reproduced from Every Death Counts report $\frac{11}{}$ with permission from author and publisher. Data for primary causes of maternal deaths from Saving Mothers 2002-04 report; $\stackrel{2}{-}$ for primary causes of stillbirths from Saving Babies 2003-05 report; $\stackrel{3}{-}$ and for causes of death 
for children younger than 5 years and those younger than 1 month derived from the 2000 South Africa Burden of Disease estimates. $\stackrel{[11]}{ }$ and [33]

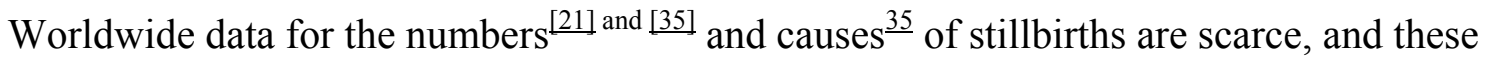
deaths are still largely unreported. Through PPIP, South Africa captures information about many of these deaths; however, around a third of stillbirths still remain unexplained. ${ }^{3}$ PPIP suggests that intrapartum stillbirths and antepartum haemorrhage together account for $29 \%$ of all stillbirths (figure 2). These intrapartum stillbirths are eminently preventable with appropriate care during childbirth.

Causes of death in neonates and in those younger than 5 years are most difficult to obtain from the facility audit data. Child PIP is still fairly new and in too few sites for use as a source for national cause of death. Although Child PIP originally obtained only medical causes of death, thus missing injury deaths, it is expanding to include surgical causes. Capturing all neonatal deaths is especially challenging. PPIP captures mainly neonatal deaths before discharge, missing some early neonatal deaths after discharge and most late neonatal deaths. Child PIP captures infants and children admitted to the paediatric ward, which should include late neonatal admissions. Late neonatal deaths can be recorded either in PIPP or in Child PIP, dependent on circumstances, or in neither if the death occurred at home. Reliance on one audit system without combining both datasets will result in an underestimation of neonatal deaths.

The primary purpose of these audits is to identify factors implicated in every avoidable death, and therefore the cause of death classification is not always consistent with International Classification of Disease (ICD) rules for coding cause of death with one cause. For example, by obtaining detail from laboratory tests and information about HIV clinical stage on every child who died, Child PIP is able to provide detailed cause-ofdeath profiling for children with HIV, including immediate cause of death, such as pneumonia, which can be missed in the ICD coding approach since HIV (if present) is always listed as the direct cause. Hence, audit data for cause of death cannot be directly comparable with other sources. In view of these differences, the data for cause of death presented here are based on South Africa's national burden of disease study ${ }^{[33]}$ and $[36]$ with use of population-based proportionate data for cause of death from 1996, updated for 2000, and revised to use programmatically relevant causes of death categories in the neonatal period rather than the perinatal causes. ${ }^{[37]}$ and [38]

Neonatal causes, childhood infections such as pneumonia and diarrhoea, and HIV/AIDS each account for roughly $30 \%$ of all child deaths. Deaths during the first month of life, the time of highest risk for child death, are due to three main causes: infections, complications of preterm birth, and birth asphyxia. Improved intrapartum care would prevent most of the deaths of the 4500 babies dying of birth asphyxia every year and would also reduce intrapartum stillbirths.

Malnutrition contributes to child mortality by increasing the risk of death, especially that due to infections. ${ }^{39}$ Child PIP data show that $60 \%$ of children who died were underweight for age and a third were severely malnourished $(Z$ score $\leq-3) .{ }^{4}$ However, cross-analysis shows that $75 \%$ of the children dying who were severely malnourished had clinical 
criteria that was compatible with stage III or IV HIV/AIDS. ${ }^{4}$ Hence for most of these severely malnourished children, HIV infection has resulted in a vicious cycle of infection and undernutrition. Improved HIV prevention and management should reduce the prevalence of malnutrition and the risk of child death.

Most maternal and child deaths fall into five categories: HIV/AIDS, pregnancy and childbirth complications, neonatal illness, childhood illness, and malnutrition, which are all linked to poverty and great inequity. A report ${ }^{11}$ has named these causes of death as South Africa's big five health challenges that need to be overcome to progress towards the health-related MDGs.

All three national audit reports identify modifiable factors related to every death, where they occur, and those who are responsible for change- - health-care providers, health administrators, and the family or community. The table shows the distribution of modifiable factors from the three audits. Although the highest percentages of causes are at the interface of health care and the provider, a high percentage of avoidable factors occur within the community for mothers, babies, and children (table). These communitybased modifiable factors are predominantly delays in recognising danger signs and seeking care. Additionally, between $22 \%$ and $32 \%$ of deaths were related to administrative modifiable factors, such as transport failure. Some important modifiable factors outside the scope of the facilities emphasise that the health-care system alone is not sufficient to save these lives-wider accountability is needed.

\begin{tabular}{|c|c|c|c|}
\hline & Pannlly and commentifye & 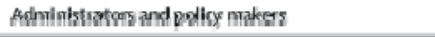 & Haltheresepriders \\
\hline 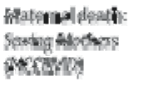 & 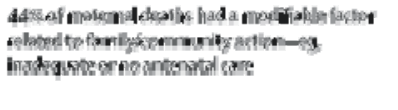 & 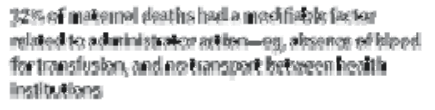 & 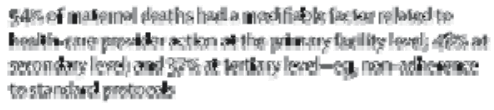 \\
\hline 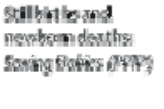 & 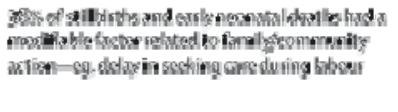 & 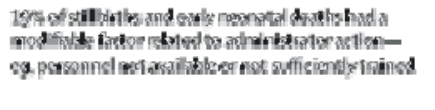 & 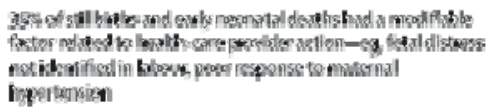 \\
\hline 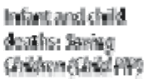 & 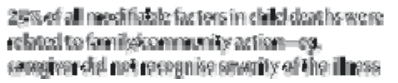 & 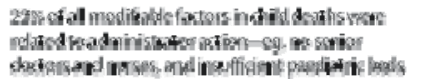 & 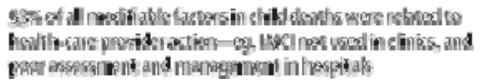 \\
\hline
\end{tabular}

Child $\mathrm{PIP}=$ child healthcare problem identification programme. $\mathrm{PPIP}=$ perinatal problem identification programme

NCCEMD=National Committee on Confidential Enquiries into Maternal Deaths. IMCI=Integrated Management of Childhood Illness.

Table. Modifiable factors underlying the deaths of mothers, babies, and children in South Africa, according to the three national mortality audits $[2],[3]$ and $[4]$

\section{Coverage and quality of care}

At all levels of the health system, South Africa has health-service packages throughout the lifecycle for mothers, babies, and children, which together form the basis of an effective continuum of care. ${ }^{40}$ Figure 3 shows national coverage for key interventions for the health of mothers, babies, and children. Little information exists in the postnatal period and for the characteristic cascade of HIV interventions through the years. Despite fairly high coverage of most of the major packages, including antenatal care, skilled birth attendance, and Integrated Management of Childhood Illness (IMCI), coverage of some 
important effective interventions and quality of care within existing packages is low. Audit has a role, especially in improving quality of care for all these key packages.

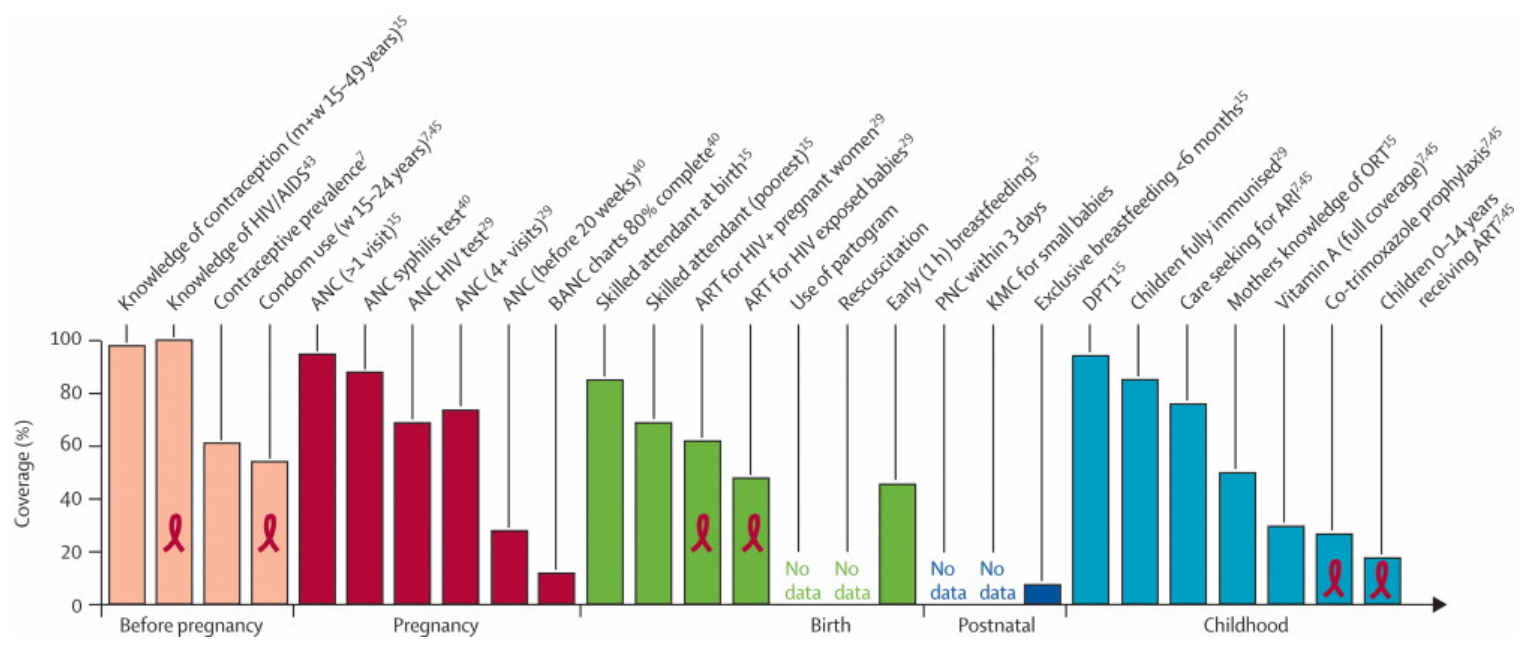

Figure 3. Coverage of maternal, newborn, and child health packages by time

Figure shows coverage and quality gaps, and emphasises the gap around the time of childbirth and postnatal care and cascading HIV interventions. Red ribbon denotes HIV-specific indicators. $\mathrm{ANC}=$ antenatal care. $\mathrm{BANC}=$ basic antenatal care package.

$\mathrm{ART}=$ antiretroviral therapy. $\mathrm{KMC}=\mathrm{Kangaroo}$ Mother Care. $\mathrm{BF}=$ breastfeeding. $\mathrm{DPT}=$ diphtheria, pertussis, tetanus vaccination.

$\mathrm{ARI}=$ acute respiratory infection. $\mathrm{PNC}=$ postnatal care. $\mathrm{ORT}=$ oral rehydration therapy. $\mathrm{W}=$ women. $\mathrm{M}=$ men. Reproduced from Every

Death Counts report ${ }^{11}$ with permission from author and publisher.

Sexual and reproductive health services have improved in recent years. The rate of contraception use is $60 \%,{ }^{7}$ and the seroprevalence of syphilis in pregnant women who are tested at antenatal clinics has decreased in all age groups. ${ }^{29}$ However, despite the introduction of the Choice on Termination of Pregnancy Act a decade ago, one study from the Western Cape showed that a third of women did not know that abortion is legal. $\stackrel{41}{ }$ Another study noted that women even in metropolitan areas still self-medicated and sought traditional healers, mainly because of little information about abortion rights and perceived poor quality of designated facilities. ${ }^{42}$

Coverage of antenatal care is very high, with $94 \%$ of women attending at least one antenatal visit. However, the timing, number, and content of these visits are not optimum for all women. For example, only $73 \%$ of women attend up to four visits,,$\frac{15}{}$ and one audit of antenatal cards showed that only $11 \%$ of more than 3000 cards from districts across the country scored $80 \%$ or more for completeness of interventions undertaken and recorded during antenatal visits. ${ }^{43}$ NCCEMD data show that $68 \%$ of women who died of infections unrelated to pregnancy (such as AIDS) attended antenatal care, and women who did not attend antenatal care had a four-fold risk of maternal death compared with the overall pregnant population. ${ }^{2}$ Hence, closing the coverage gap to reach the other $32 \%$ is important, and there is an immediate opportunity to save lives in the $68 \%$ of women already accessing care, representing a quality gap.

Childbirth services are widely available at primary health-care facilities, midwife obstetric units, and district and regional hospitals, but the quality of care that is provided varies. $84 \%$ of women are assisted by a skilled attendant at birth, which is much higher 
than the African average, but still lower than antenatal-care attendance in South Africa. ${ }^{15}$ Little is known about the level of health care received by the estimated 230000 women who give birth outside of a health facility every year. The national caesarean section rate

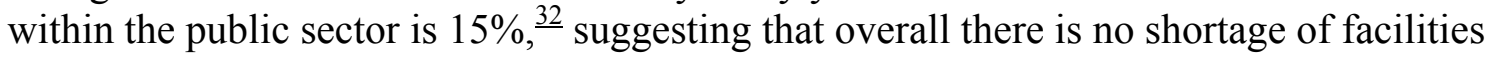
that can provide emergency obstetric care. However, these services are not equitably distributed, $\underline{44}$ or even where available the caesarean section might be provided too late. $\underline{45}$ $\mathrm{KMC}$ for preterm babies is one success arising from the audit process, and is now being practised widely (panel 2). According to a survey of PPIP users, 90\% of hospitals reported that they had implemented some form of KMC by January, 2005. 24 of these institutions had created a special ward for such care. $\underline{14}$

Routine care during the postnatal period is scarce in South Africa, as it is in most developing countries. Postnatal care in particular needs strong links between the community and health facility to encourage healthy practice in the home, such as appropriate infant feeding. Although $46 \%$ of women breastfeed within $1 \mathrm{~h}$ after birth, only $7 \%$ of infants are exclusively breastfed for up to 6 months, which is one of the lowest rates on the continent. ${ }^{7}$ The postnatal period is crucial for counselling about infant feeding options, family planning, and prevention of mother-to-child transmission of HIV, yet until recently there has been no national policy for timing or content of routine postnatal visits. The present policy promotes a facility visit within 3 days of birth and again at 6 weeks, but few providers are aware of this policy. Essential Postnatal Care is a programme that aims to implement the policy. It uses checklists and patient-held cards to communicate between the hospital and local clinic. The programme is at too early a stage to make conclusions about its effectiveness, but the first 6 weeks of life remain an important gap in care.

Key indicators of some outreach services for child health are high, with coverage of immunisation of BCG, DPT3, and hepatitis B all greater than $90 \%{ }^{7}$ Coverage for nutrition interventions is a coverage gap - only $29 \%$ of children younger than 5 years received two doses per year of vitamin A. ${ }^{7}$ Only half of caregivers have adequate knowledge of oral rehydration therapy, ${ }^{7}$ despite a national incidence rate of 258 new cases of diarrhoeal disease per 1000 children. $\frac{32}{75 \%}$ of caregivers are able to seek care for acute respiratory infection; ${ }^{7}$ however, according to Child PIP data, only $22 \%$ of children dying with suspected or confirmed pneumocystis pneumonia received cotrimoxazole prophylaxis. ${ }^{4}$ Clinical services for children are more difficult to assess since the IMCI obtains process indicators (eg, number of staff trained) rather than population coverage.

Knowledge of HIV/AIDS and prevention methods is consistently high in South African adolescents, ${ }^{46}$ but coverage of interventions for HIV/AIDS prevention and treatment decreases along the continuum of care. The associated stigma and no continuity of care means that often a patient's HIV status remains unknown, resulting in little crucial follow-up - eg, antiretroviral drugs and appropriate feeding for babies and continual treatment for mothers. According to national targets, all clinics in South Africa should offer prevention services for mother-to-child transmission of HIV, including HIV testing. ${ }^{47}$ However, only seven of the 52 districts in South Africa are testing more than 
$80 \%$ of women attending antenatal clinics,,$\frac{32}{2}$ and $68 \%$ of pregnant women receiving antenatal care received an HIV test. Nevirapine uptake has increased substantially, with $61 \%$ of HIV-positive women taking this drug. .32 Drop-off occurs around the time of birth, with only $47 \%$ of babies born to HIV-positive mothers receiving nevirapine, $\frac{32}{2}$ and $26 \%$ of babies receiving co-trimoxazole prophylaxis. $\stackrel{48}{=}$ Only an estimated $18 \%$ of children aged $0-14$ years who need antiretroviral treatment are receiving it. ${ }^{48}$ No national data are available for adherence to appropriate feeding choices; however, one study documenting poor infant feeding counselling showed that two-thirds of HIV-positive mothers make inappropriate infant feeding choices, resulting in a three-fold increased risk of their infant becoming infected with HIV or dying. [49] and [50]

South Africa has three important gaps in care. First, the coverage gap between present coverage and universal coverage - eg, the gap between skilled attendance at $84 \%$ and full coverage at $100 \%$. 15 Second, the quality gap between the coverage of a package or contact opportunity and an effective intervention that can be provided through that package - eg, the gap between the percentage of pregnant women attending at least one antenatal care visit $(94 \%)^{15}$ and first antenatal visit before 20 weeks $(27 \%) . \stackrel{43}{ }$ Third, the equity gap between coverage for the poorest quintile and the richest quintile - eg, the gap between women from the richest and poorest families receiving skilled attendance is $30 \%$ $\left(98 \%\right.$ and $68 \%$, respectively). $\frac{15}{}$

Overall for South Africa, coverage for most interventions is higher than is the median coverage for the 68 priority countries in the Countdown programme. ${ }^{51}$ Postnatal care is a notable exception, with few data and low coverage. Coverage of referral care is generally lower than is that for primary care. Although referral care is available free of charge to mothers and children, it might not be always available at the time and place that they are needed, especially in rural areas. With high coverage, the priority is to close the quality and equity gap. Audit is especially useful for quality improvement, but it can also be used to identify and target inequities in direct provision of care. However, addressing wider inequity and social determinants needs high-level commitment and intersectoral action.

\section{Accountability for action}

Audit is only effective if there is accountability for action so that recommendations are implanted and assessed - ie, closing the audit loop to result in a cycle of upward quality improvement. Individuals can make a big difference, in some cases even quickly catalysing local changes in processes (panel 2). However, a scarcity of human resources, health-facility infrastructure, and supply systems can be so fundamental that although local process can be improved, the effect at the population level can be restricted. These larger shifts in health system need government stewardship, district-level management, monitoring, and an expressed focus on addressing inequity. Intersectoral collaboration can also be necessary with commitment from education, transport, and financial stakeholders. These wider constraints and the solutions that are needed cannot all be dealt with in one paper. 
The three groups of responsible people who have been identified by the audit reports all have a part to play to improve the health of mothers, babies, and children, and overall efforts to strengthen health systems. The most direct results from any audit process will be the changes that can be made by health-care providers in their immediate domain. A review of intervention studies in developing countries suggests that supervision and audit with feedback is generally effective in the improvement of the performance of health workers. $\stackrel{52}{~ F o r ~ e x a m p l e, ~ i n ~ W i t b a n k ~ H o s p i t a l ~ i n ~ M p u m a l a n g a ~ p r o v i n c e, ~ h e a l t h-c a r e ~}$ providers were able to record changes in a fairly short period for reduction of child death, with a change in local protocol to opt-out of testing for HIV and improved counselling skills (panel 2). Quality of care is also dependent on the number of staff with the appropriate skills mix - South Africa has a shortage of health professionals and inequitable deployment of existing staff. .53 Despite the provision of high-quality medical education, South Africa has the disadvantage of the so-called brain drain, with staff moving overseas and to the private sector. One analysis shows a discrepancy between expected and actual staff, with some of the poorest districts having only $7 \%$ of the required number of doctors. ${ }^{53}$ By contrast, $94 \%$ of the required number of professional nurses were present, but there were wide variations between districts with some having excesses and others having shortages. A functioning supervisory and management system have been common factors in local interventions that have improved the performance of health-care workers, as shown in assessments of IMCI $\underline{54}$ and the WHO severe malnutrition protocols. $\underline{55}$

Quality services are dependent on health-system components relating to the administration of sites such as adequate infrastructure and equipment, and supplies such as drugs and disposables. Administrators need to have a quality-improvement mindset and process (with appropriate norms and standards), preservice and in-service training, and supervision. Throughout the lifetime of audit reports, important recommendations have been repeated that have not resulted in sustained national change. This finding can also apply to individual facilities, in which data have emphasised major gaps and yet administrative follow-up has been challenging. One high profile example is at Frere Hospital in Eastern Cape, which captured media attention in 2007 when PPIP data reported the number of newborn deaths and linked shortcomings in quality of care, human resources, and equipment. ${ }^{[56]}$ and ${ }^{[57]}$ However, although the number of deaths had risen, births had also increased, thus the rate of stillbirth and neonatal death before discharge were fairly constant. ${ }^{-5}$ Many other hospitals in South Africa have much the same or higher mortality rates, and solutions have to reach more than this one hospital and should be sustained even when media attention wanes.

The modifiable factors in all three reports draw attention to gaps in family knowledge contributing to unhealthy behaviours and delay in seeking care (table). Health-care providers, administrators, and policy makers can strengthen links with the community, including solutions involving empowerment and addressing equity issues. Involvement of the community in a partner-defined quality process, rather than limiting the solutions to

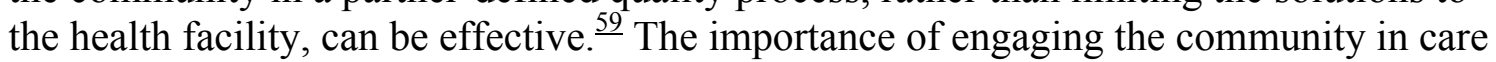
is emphasised by the high number of orphans and vulnerable children; according to Child PIP, in $7 \%$ of child deaths the mother was also dead, and in $9 \%$ she was sick. ${ }^{4}$ 
Grandparents were the primary caregiver in $13 \%$ of child deaths. ${ }^{4}$ Grants for child support are successful, with increasing uptake for the poorest families. $\frac{60}{}$ A nationally agreed set of family-health messages, promoted by all sectors, is recommended as a solution for gaps and to address other key priorities in behaviour change. ${ }^{2}$

\section{Conclusions}

Much has been achieved during the first 14 years of democracy in South Africa, but many paradoxes remain. At least 260 women, babies, and children die every day in South Africa, and no measurable progress has been made to reduce this mortality rate. This toll is too high in view of South Africa's status as a middle-income country and capacity to provide services. HIV/AIDS, complications from pregnancy and childbirth, newborn illness, childhood illness, and malnutrition are the priority challenges to meet the healthrelated MDGs. The existing high coverage of many key interventions presents an opportunity to save lives by focusing on high-quality services and integration of HIV/AIDS care, while addressing inequity by reaching the poorest and marginalised populations. National mortality audit for mothers, babies, and children are an achievement and present recommendations and strategies to save lives. The new Every Death Counts report ${ }^{11}$ brings these aims together as one harmonised set of recommendations. However, if South Africa is to see a reduction in maternal, neonatal, and child mortality, these recommendations need to be fully implemented to turn mortality data into action. This goal needs accountability at all levels. Then every death will truly count.

\section{Every Death Counts Writing Group}

Debbie Bradshaw (Burden of Disease Research Unit, Medical Research Council, Cape Town, South Africa); Mickey Chopra (Health Systems Research Unit, Medical Research Council, Cape Town, South Africa); Kate Kerber (Saving Newborn Lives/Save the Children-US, Cape Town, South Africa); Joy E Lawn (Saving Newborn Lives/Save the Children-US, and Health Systems Research Unit, Medical Research Council, Cape Town, South Africa); Lesley Bamford (School of Health Systems and Public Health, University of Pretoria, Pretoria, South Africa); Jack Moodley (Womens' Health and HIV Research Group, University of KwaZulu-Natal, KwaZulu-Natal, South Africa); Robert Pattinson (MRC Maternal and Infant Heath Care Strategies Research Unit, University of Pretoria, Pretoria, South Africa); Mark Patrick (Department of Paediatrics, Pietermaritzburg Hospitals Complex and MRC Maternal and Infant Health Care Strategies Research Unit, University of Pretoria, Pretoria, South Africa); Cindy Stephen (Department of Paediatrics, Pietermaritzburg Hospitals Complex and MRC Maternal and Infant Health Care Strategies Research Unit, University of Pretoria, Pretoria, South Africa); and Sithembiso Velaphi (Department of Paediatrics, University of the Witwatersrand, Johannesburg, South Africa).

\section{Conflict of interest statement}

We declare that we have no conflict of interest. 


\section{Acknowledgments}

Saving Children and Saving Babies coordinators acknowledge the support of the US Centers for Disease Control and Prevention (CDC) for their generous funding of the Child PIP project and for the printing of the reports. The Every Death Counts report writing and production was facilitated through a grant from the Bill \& Melinda Gates Foundation to Save the Children Federation for the Saving Newborn Lives programme.

\section{References}

1 J Bryce, J Requejo and the 2008 Countdown Working Group, Tracking progress in maternal, newborn, and child survival: the 2008 report http://www.countdown2015mnch.org (accessed April, 2008). $\underline{2}$ National Department of Health, Saving mothers: third report on confidential inquiries into maternal deaths in South Africa, 2002-04, National Department of Health, Pretoria (2007).

$\underline{3}$ Saving babies 2003-05: fifth perinatal care survey of South Africa, University of Pretoria, Medical Research Council of South Africa, Centres for Disease Control, Pretoria (2007).

4 M Patrick and C Stephen, Saving children 2005: a survey of child healthcare in South Africa, MRC Unit for Maternal and Infant Health Care Strategies, Pretoria (2007). 5 PW Setel, SB Macfarlane and S Szreter et al., A scandal of invisibility: making everyone count by counting everyone, Lancet 370 (2007), pp. 1569-1577. 6 South African Statistics Council, Mid-year population estimates, 2007, Statistics South Africa, Pretoria (2007).

7 UNICEF, State of the World's Children 2008, United Nations Children's Fund (UNICEF), New York (2008).

$\underline{8}$ K Kahn, Dying to make a fresh start: mortality and health transition in a new South Africa. Umea university medical dissertations new series number 1056, Umea University, Umea (2006).

9 D Bradshaw, M Schneider, R Dorrington, DE Bourne and R Laubscher, South African cause-of-death profile in transition-1996 and future trends, S Afr Med J 92 (2002), pp. $618-623$.

10 EH Burger, L van der Merwe and J Volmink, Errors in the completion of the death notification form, S Afr Med J 97 (2007), pp. 1077-1081.

11 Every Death Counts writing group, Every death counts: saving the lives mothers, babies and children in South Africa, National Department of Health, Medical Research Council, University of Pretoria, Save the Children, UNICEF, Cape Town (2008).

$\underline{12}$ R Pattinson, D Woods, D Greenfield and S Velaphi, Improving survival rates of newborn infants in South Africa, Reprod Health 2 (2005), p. 4.

13 RC Pattinson, I Arsalo, AM Bergh, AF Malan, M Patrick and N Phillips, Implementation of kangaroo mother care: a randomized trial of two outreach strategies, Acta Paediatr 94 (2005), pp. 924-927.

14 RC Pattinson, AM Bergh, AF Malan and R Prinsloo, Does kangaroo mother care save lives?, J Trop Pediatr 52 (2006), pp. 438-441. 
15 National Department of Health, Medical Research Council, Measure DHS, 1998 South Africa demographic and health survey, Measure DHS, Calverton, MD (2002).

$16 \mathrm{~F}$ Baiden, A Bawah and S Biai et al., Setting international standards for verbal autopsy, Bull World Health Organ 85 (2007), pp. 570-571.

17 R Dorrington, D Bradshaw, L Johnson and L Daniel, The demographic impact of HIV/AIDS in South Africa: national and provincial indicators 2006, Centre for Actuarial Research, South African Medical Research Council, Actuarial Society of South Africa, Cape Town (2006).

18 C Murray, T Laasko, K Sibuya, K Hill and A Lopez, Can we achieve Millennium Development Goal 4 ? New analysis of country trends and forecasts of under-5 mortality to 2015 , Lancet 370 (2007), pp. 1040-1054.

19 US Census Bureau, Country summary: South Africa http://www.census.gov/ipc/www/idb/country/sfportal.html (accessed March 15, 2008). 20 UN, Department of Economic and Social Affairs, Population Division (2007), World population prospects: the 2006 revision, highlights, working paper number ESA/P/WP.202, United Nations Population division, New York (2007).

21 WHO, Perinatal and neonatal mortality for the year 2000: country, regional, and global estimates, World Health Organization, Geneva (2006).

22 L Say, M Inoue, S Mills and E Suzuki, Maternal mortality in 2005: estimates

developed by WHO, UNICEF, UNFPA, and the World Bank, World Health Organization, Geneva (2007).

$23 \mathrm{D}$ Bradshaw and R Dorrington, Child mortality in South Africa-we have lost touch, S Afr Med J 97 (2007), pp. 582-583.

24 RE Dorrington, TA Moultrie and IM Timaeus, Estimation of mortality using the South African Census 2001 data, Centre for Actuarial Research, Cape Town (2004).

25 SR Fawcus, HA van Coeverden de Groot and S Isaacs, A 50-year audit of maternal mortality in the Peninsula Maternal and Neonatal Service, Cape Town (1953-2002), BJOG 112 (2005), pp. 1257-1263.

$26 \mathrm{~K}$ Hill, $\mathrm{K}$ Thomas and C AbouZahr et al., Estimates of maternal mortality worldwide between 1990 and 2005: an assessment of available data, Lancet 370 (2007), pp. 13111319 .

$27 \mathrm{C}$ AbouZhar and T Wardlaw, Maternal mortality in 2000: estimates developed by WHO, UNICEF and UNFPA, World Health Organization, Geneva (2003), pp. 1-39. 28 UNICEF, Progress for children: a world fit for children statistical review, UNICEF, New York (2007).

$\underline{29}$ National HIV and syphilis antenatal sero-prevalence survey in South Africa: 2006, South Africa Department of Health, Pretoria (2007).

$\underline{30} \mathrm{H}$ Schneider and L Gilson, The impact of free maternal health care in South Africa, Reprod Health Matters 8 (2000), pp. 55-65.

$31 \mathrm{D}$ McIntyre and M Thiede, Healthcare financing and expenditure. In: S Harrison, R Bhana and A Ntuli, Editors, South African health review 2007, Health Systems Trust, Durban (2007).

32 P Barron, C Day and F Monticelli et al., The district health barometer 2005/06, Health Systems Trust, Durban (2006). 
$\underline{33}$ R Norman, D Bradshaw, M Schneider, D Pieterse and P Groenwald, Revised burden of disease estimates for the comparative risk factor assessment, South Africa 2000, Medical Research Council, Cape Town (2006). 34 Government of South Africa, Choice on Termination of Pregnancy Act. Act 92, Government Printer, Pretoria (1996).

$35 \mathrm{~J}$ Lawn, K Shibuya and C Stein, No cry at birth: global estimates of intrapartum stillbirths and intrapartum-related neonatal deaths, Bull World Health Organ 83 (2005), pp. 409-417.

$36 \mathrm{D}$ Bradshaw, P Groenewald and R Laubscher et al., Initial burden of disease estimates for South Africa, 2000, S Afr Med J 93 (2003), pp. 682-688.

37 JE Lawn, S Cousens and J Zupan, 4 million neonatal deaths: when? Where? Why?, Lancet 365 (2005), pp. 891-900.

$\underline{38} \mathrm{JE}$ Lawn, K Wilczynska-Ketende and SN Cousens, Estimating the causes of 4 million neonatal deaths in the year 2000, Int J Epidemiol 35 (2006), pp. 706-718.

39 RE Black, LH Allen and ZA Bhutta et al., Maternal and child undernutrition: global and regional exposures and health consequences, Lancet 371 (2008), pp. 243-260. 40 KJ Kerber, JE de Graft-Johnson, ZA Bhutta, P Okong, A Starrs and JE Lawn, Continuum of care for maternal, newborn, and child health: from slogan to service delivery, Lancet 370 (2007), pp. 1358-1369.

41 C Morroni, L Myer and K Tibazarwa, Knowledge of the abortion legislation among South African women: a cross-sectional study, Reprod Health 3 (2006), p. 7. $\underline{42}$ RK Jewkes, T Gumede, MS Westaway, K Dickson, H Brown and H Rees, Why are women still aborting outside designated facilities in metropolitan South Africa?, BJOG 112 (2005), pp. 1236-1242.

$\underline{43}$ RC Pattinson, E Etsane and J Snyman et al., Report to UNICEF on the scaling-up of the Basic Antenatal Care quality improvement programme in two sub-districts per province in South-Africa (draft), MRC Maternal and Infant Health Care Strategies Research Unit and the University of Pretoria, Pretoria (2007). 44 P Barron, The District Health Barometer 2007 (in press), Health Systems Trust, Durban (2008).

45 EJ Buchmann, RC Pattinson and N Nyathikazi, Intrapartum-related birth asphyxia in South Africa-lessons from the first national perinatal care survey, S Afr Med J 92 (2002), pp. 897-901.

46 National Department of Health, Measure DHS, 2003 South Africa Demographic and Health Survey, Preliminary Report, ORC Macro, Calverton, MD (2004).

47 South African National AIDS Council, HIV \& AIDS and STI National Strategic Plan 2007-011, National Department of Health, Pretoria (2007).

$\underline{48}$ UNICEF, Stocktaking report on children and AIDS http://0www.unicef.org.innopac.up.ac.za/publications/index 38048.html (accessed March 15, 2008).

49 DJ Jackson, M Chopra and TM Doherty et al., Operational effectiveness and 36 week HIV-free survival in the South African programme to prevent mother-to-child transmission of HIV-1, AIDS 21 (2007), pp. 509-516.

50 M Chopra, T Doherty, D Jackson and A Ashworth, Preventing HIV transmission to children: quality of counselling of mothers in South Africa, Acta Paediatr 94 (2005), pp. $357-363$. 
51 Countdown Coverage Writing Group, on behalf of the Countown to 2015 Core Group, Countdown to 2015 for maternal, newborn, and child survival: the 2008 report on tracking coveration of interventions, Lancet 371 (2008), pp. 1247-1258.

52 AK Rowe, SD de, CF Lanata and CG Victora, How can we achieve and maintain high-quality performance of health workers in low-resource settings?, Lancet 366 (2005), pp. 1026-1035.

$\underline{53}$ E Daviaud and M Chopra, How much is not enough? Human resources requirements for primary health care: a case study from South Africa, Bull World Health Organ $\mathbf{8 6}$ (2008), pp. 46-51.

54 M Chopra, S Patel, K Cloete, D Sanders and S Peterson, Effect of an IMCI intervention on quality of care across four districts in Cape Town, South Africa, Arch Dis Child 90 (2005), pp. 397-401.

55 A Ashworth, M Chopra and D McCoy et al., WHO guidelines for management of severe malnutrition in rural South African hospitals: effect on case fatality and the influence of operational factors, Lancet 363 (2004), pp. 1110-1115.

56 SABC News, Tough year for SA Health Department http://www.sabcnews.com/south_africa/health/0,2172,161663,00.html (accessed March 15, 2008).

$\underline{57}$ F Forde, Frere Hospital in the spotlight again. Cape Argus, 2007 http://www.iol.co.za/index.php?click_id=13\&set_id=1\&art_id=vn20070818105447498C 105522 (accessed March 15, 2008).

$\underline{58}$ R Green-Thompson, T Sibeko and N Khaole, National Task Team Report on Frere Hospital http://0-www.doh.gov.za.innopac.up.ac.za/docs/misc/frere/task_team_report.pdf (accessed March 15, 2008).

$\underline{59}$ R Lovich, M Rubardt, D Fagan and M Powers, Partnership defined quality: a tool for partnership and health provider collaboration, Save the Children USA, Westport CT (2003).

60 Case A, Hosegood V, Lund F. The reach of the South African child support grant: evidence from KwaZulu-Natal. University of Natal, Durban, Centre for Social and Development Studies Working Paper 38, Princeton University, Research Program in Development Studies Working Paper 224, 2003. 